\title{
PENINGKATAN HASIL BELAJAR MATEMATIKA MELALUI MODEL PROBLEM BASED LEARNING DENGAN PENDEKATAN SAINTIFIK PADA SISWA KELAS VI SD ISLAM 34 AL AZHAR MAKASSAR
}

\author{
Diani Asbasari Jarsyah ${ }^{1 *}$, Irfawandi Samad ${ }^{2}$ \\ ISD Al Azhar Makassar \\ 2Universitas Al Asyariah Mandar \\ *Email: dianiasbasari@gmail.com
}

\begin{abstract}
This type of research uses Classroom Action Research using two cycles. Each cycle consists of 4 stages, namely 1) action planning, 2) action implementation, 3) observation, 4) reflection. The purpose of this research is to improve the Problem Based Learning model through a scientific approach. The location of the research was carried out at the Islamic Elementary School 34 Al Azhar Makassar, South Sulawesi Province, class VI with 26 students with 16 male students and 11 female students. In the first cycle the percentage level is 57.69 with a frequency value of 15 in the incomplete category, the percentage level is 42.31 with a frequency value of 11 in the complete category. In cycle II the percentage level is 11.53 with a frequency value of 3 in the incomplete category, the percentage level is 88.47 with a frequency value of 23 in the complete category. The results of the qualitative and quantitative data show that the mathematics learning outcomes of SD Islam 34 Al Azhar Makassar on the Poblem Based Learning model through a scientific approach there is an increase in student learning outcomes.
\end{abstract}

Keywords: problem based learning, scientific approach, learning outcomes

\section{PENDAHULUAN}

Pendidikan merupakan salah satu cara pembentukan kemampuan manusia untuk menggunakan rasional seefektif dan seefisien mungkin sebagai jawaban dalam menghadapi masalah-masalah yang timbul dalam usaha menciptakan masa depan yang baik. Untuk meningkatan mutu pendidikan merupakan kebutuhan yang sangat mendasar sebab keberhasilan suatu bangsa diperlukan keberadaan sumber daya manusia yang berkualitas (Anwar 2015). Peranan guru merupakan faktor penentu keberhasilan proses pembelajaran yang berkualitas. Sehingga berhasil tidaknya pendidikan mencapai tujuan selalu dihubungkan dengan kiprah para guru. Oleh karena itu, usaha-usaha yang dilakukan dalam meningkatkan mutu pendidikan hendaknya dimulai dari 
peningkatan kualitas guru. Guru yang berkualitas diantaranya adalah mengetahui dan mengerti peran dan fungsinya dalam proses pembelajaran (Rusman, 2012).

Proses pembelajaran boleh terjadi manakala ada interaksi antara guru dan siswa atau hubungan timbal balik antara siswa dengan lingkungannya dalam situasi edukatif untuk mencapai tujuan yang telah ditetapkan. Hubungan timbal balik ini merupakan syarat terjadinya proses pembelajaran yang di dalamnya tidak hanya menitikberatkan pengetahuan siswa. Hal ini guru adalah sebagai media yang mutlak adanya dalam proses pembelajaran siswa (Soedjadi 2004).

Matematika merupakan salah satu mata pelajaran yang dapat menumbuhkan kemampuan penalaran. Matematika adalah mata pelajaran yang harus diberikan di semua tingkat pengajaran dari sekolah dasar hingga tingkat perguruan tinggi. Matematika sangat penting untuk siklus komputasi dan proses berpikir dalam menangani berbagai masalah yang terjadi dalam kehidupan seharihari (Karo-Karo 2016).

Dengan demikian dari hasil pengamatan dikelas bahwa kesulitan menyelesaikan sisi ketika luas permukaan telah di ketahui pada bangun ruang sisi datar. Dalam belajar matematika bukan semata-mata pada materi pelajaran matematika saja, tetapi juga disebabkan karena kemampuan siswa dalam kurang memahami konsep, symbol dan kurangnya menganalisa soal sehingga pembelajaran matematika kurang efektif.

Hal tersebut diakibatkan karena kurang aktifnya kegiatan pembelajaran siswa dalam proses belajar mengajar. Sehingga siswa umumnya mengerti ketika guru telah menjelaskan materi di kelas akan tetapi ketika dihadapkan pada penyelesaian soal-soal maka siswa masih banyak melakukan kesalahan. Selain itu dalam menyelesaikan masalah, memahami konsep dan kurangnya keaktifan siswa dalam pembelajaran maka dapat mempengaruhi hasil belajar siswa (Suhartini 2009).

Untuk memahami persoalan diatas dalam menyelesaikan masalah maka guru menerapkan metode dan pendekatan yang dapat mendorong siswa untuk menyelesaikan permasalahan sendiri. Salah satu metode dalam penerapan menyelesaikan masalah yaitu Problem Based Learning (PBL). Problem Based Learning merupakan suatu metode pembelajaran yang bekerja secara berkelompok untuk mencari solusi dalam masalah dunia nyata (Pratama, Lestari, and Jailani 2018). Model pembelajarannya adalah Problem Based Learning (PBL) atau pembelajaran berbasis masalah. Model pembelajaran PBL menemukan bahwa menyoroti siswa seperti pada masalah yang valid atau signifikan yang akan dibahas dengan memanfaatkan semua wawasan mereka atau dari sumber yang berbeda. Pemanfaatan model Problem Based Learning (PBL) dengan media substansial dapat menjadi upaya dalam mengembangkan hasil belajar matematika lebih lanjut(Nuraini 2017). 
Hal ini dengan alasan bahwa model pembelajaran berbasis masalah (PBL) mengangkat masalah sebagai tahap awal dalam mengumpulkan dan mengkoordinasikan informasi baru. Pembelajaran berbasis masalah adalah teknik pembelajaran yang dimulai dengan isu untuk mengumpulkan dan menggabungkan informasi baru. Dengan tujuan akhir untuk mengatasi masalah ini, siswa akan mendapatkan informasi dan kemampuan yang dibutuhkan untuk masalah ini. Sistem pembelajaran dimulai dengan mengkarakterisasi masalah, kemudian, pada saat itu, mempelajari percakapan langsung untuk menyeimbangkan wawasan tentang masalah yang diperiksa dan kemudian merencanakan tujuan dan fokus yang akan dicapai.

Tindakan berikut adalah mencari bahan dari berbagai sumber seperti buku di perpustakaan, web, persepsi. Evaluasi yang dilakukan oleh pendidik tidak hanya pada hasil belajar siswa tetapi juga pada siklus yang diupayakan selama pembelajaran. Tugas pendidik disini adalah menyaring kemajuan belajar siswa untuk mencapai tujuan pembelajaran. Pendidik juga dipercayakan untuk mengkoordinir siswa dalam menangani masalah yang diberikan agar mereka tetap pada posisi yang tepat.(Soedjadi 2004)

Proses pembelajaran berbasis masalah (PBL) adalah menerapkan pembelajaran yang relevan, masalah yang diperkenalkan dapat membangkitkan siswa untuk belajar, pembelajaran kejujuran adalah pembelajaran yang diyakinkan dengan masalah yang tidak terbatas, siswa secara efektif dikaitkan dengan pembelajaran, upaya koordinasi kerja, anggota Siswa memiliki kemampuan yang berbeda, pertemuan, dan ide yang berbeda. Model pembelajaran pemahaman berbasis isu menjadikan isu-isu kredibel sebagai titik fokus realisasi yang berarti membuat siswa siap untuk menangani isu-isu tersebut, sehingga siswa dipersiapkan untuk berpikir secara mendasar dan berpikir pada tingkat yang lebih signifikan (Prayogi and Asy'ari 2013).

Dalam mengaktifkan siswa dalam kegiatan pembelajaran maka diperlukan pendekatan saintifik yang diterapkan pada kerikulum 2013 dijelaskan oleh standar Permendikbud no 22 tahun 2016. Pelaksanaan pendekatan saintifik mempunyai 5 langkah yaitu mengamati, menanya, memperoleh informasi, menalar dan berkomunikasi.(Sani 2014). Pendekatan saintifik adalah interaksi pembelajaran yang direncanakan sehingga siswa secara efektif membangun ide, hukum atau standar melalui fase memperhatikan (untuk mengenali atau melacak masalah), mendefinisikan masalah, mengusulkan atau merinci spekulasi, mengumpulkan informasi dengan prosedur yang berbeda, membedah informasi, membuat kesimpulan dan memberikan ide, hukum, atau aturan yang "ditemukan"(Yanti et al. 2019).

Dengan adanya model PBL dan pendekatan saintifik secara bersama-sama memanfaatkan suatu masalah dalam pembelajaran mereka, jika dalam pendekatan PBL tahap awal pembelajaran merupakan masalah yang nyata dan 
jika cara yang logis untuk menghadapi pembelajaran menggunakan masalahmasalah yang dapat direnungkan oleh siswa. Sehingga melalui perpaduan kedua model pembelajaran tersebut dapat diterima untuk memiliki pilihan untuk membuat suatu siklus pembelajaran yang sepenuhnya mengikutsertakan siswa selama sistem pembelajaran dalam mengerjakan soal-soal numerik tergantung pada setting dalam kehidupan sehari-hari. Dari pembelajaran tersebut dapat mempersiapkan siswa untuk lebih mengembangkan potensi penalaran bepikir dalam menyelesaikan masalah dan berperan aktif dalam pembelajaran(Paloloang 2014). Oleh karena itu, model PBL dan pendekatan saintifik dapat meningkatkan hasil belajar matematika siswa di kelas VI SD 34 Al Azhar Makassar.

\section{METODE PENELITIAN}

Jenis penelitian ini menggunakan Penelitian Tindakan Kelas (PTK). Penelitian tindakan kelas ini mempunyai karekteristik di kelas dengan adanya tindakan dari tiap siklus. Tiap siklus terdiri dari 4 tahapan yaitu 1) perancanaan tindakan, 2) pelaksanaan tindakan, 3) obsevasi, 4) refleksi. Dalam tiap siklus digunakan dalam proses pembelajaran secara bersama-sama (Sugiyono 2019).

Lokasi penelitian dilaksanakan di sekolah SD Islam 34 Al Azhar Makassar Provesnsi Sulawesi Selatan. Pelaksanaan penelitian dilaksanakan pada semester ganjil tahun ajaran 2019/2021 kelas VI dengan jumlah siswa 26 dengan jumlah siswa lakilaki 16 orang dan perempuan 11 orang.

Faktor yang diselidiki dalam penelitian ini yaitu faktor input dan faktor output. Kedua faktor menjelaskan tentang proses pembelajaran untuk menyelesaikan masalah sebelum dan setelah diterapkan model pembelajaran PBL dan pendekatan saintifk. Desain penelitian tindakan kelas pada tiap siklus seperti pada gambar di bawah ini:

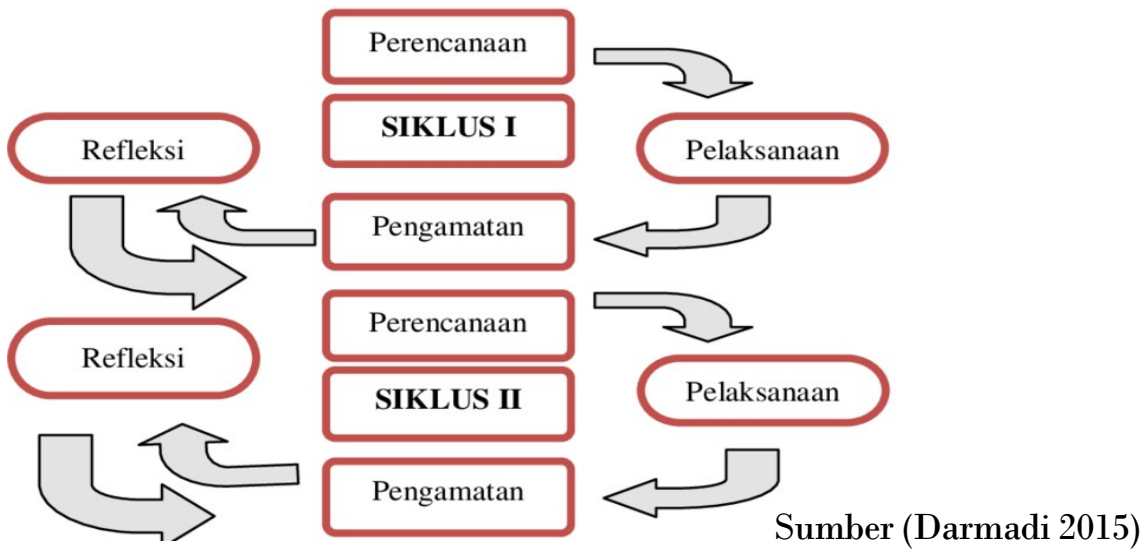

Gambar 1: Alur Tindakan Siklus 
Data yang dikumpulkan akan dianalisa secara kualitatif dan kuantitf. Adapun pengkatorian nilai sebagai berikut

Tabel 1. Tingkat Penguasaan

\begin{tabular}{|l|l|}
\hline \multicolumn{1}{|c|}{ Nilai } & \multicolumn{1}{c|}{ Kategori } \\
\hline $94 \% \leq \mathrm{TP} \leq 100 \%$ & sangat baik \\
\hline $87 \% \leq \mathrm{TP}<93 \%$ & baik \\
\hline $80 \% \leq \mathrm{TP}<86 \%$ & cukup \\
\hline $\mathrm{TP}<80 \%$ & kurang \\
\hline
\end{tabular}

Sumber : SD Islam 34 Al Azhar Makassar

Tabel 2. Kriteria Ketuntasan Secara Klasikal

\begin{tabular}{|c|c|}
\hline Persentasi KKM & Kriteria \\
\hline $0 \leq$ Persentasi KKM $<80$ & Tidak Memenuhi \\
\hline $80 \leq$ Persentasi KKM $\leq 100$ & Memenuhi \\
\hline
\end{tabular}

Sumber : SD Islam 34 Al Azhar Makassar

\section{HASIL DAN PEMBAHASAN}

Dari hasil penelitian di lapangan maka terdapat dua siklus dalam proses model pembelajaran Problem Based Learning melalui pendekatan saintifik. Adapun penerapan tiap siklus sebagai berikut:

A. Hasil Data Siklus I

Tabel 3. Data Frekuensi dan Persentase Hasil Belajar Matematika

\begin{tabular}{|c|c|c|c|}
\hline Nilai & Kategori & Frekuensi & Persentase \% \\
\hline $94 \% \leq \mathrm{TP} \leq 100 \%$ & sangat baik & 2 & 7,69 \\
\hline $87 \% \leq \mathrm{TP}<93 \%$ & baik & 6 & 23,08 \\
\hline $80 \% \leq \mathrm{TP}<86 \%$ & cukup & 3 & 11,54 \\
\hline $\mathrm{TP}<80 \%$ & kurang & 15 & 57,69 \\
\hline \multicolumn{2}{|c|}{ Jumlah } & 26 & 100 \\
\hline
\end{tabular}

(Sumber: Hasil Analisis Data, 2021)

Tabel 3 menunjukkan bahwa tingkat persentase 7,69 dengan nilai frekuensi 2 (sangat baik), tingkat persentase 23,08 dengan nilai frekuensi 6 (baik), tingkat persentase 11,54 dengan nilai frekuensi 3 (cukup), tingkat persentase 57,69 dengan nilai frekuensi 15 (kurang). Hal ini proses pembelajaran dengan tingkat penguasaan materi belum mencapai standar KKM 80.

Tabel 4. Ketuntasan Belajar Siswa

\begin{tabular}{|c|c|c|c|}
\hline Skor & Kategori & Frekuensi & Persentase \% \\
\hline $0-79$ & Tidak tuntas & 15 & 57,69 \\
$80-100$ & Tuntas & 11 & 42,31 \\
\hline
\end{tabular}


Jumlah DOI: $10.35329 /$ fkip.v17i2.2686

(Sumber: Hasil Analisis Data, 2021)

Tabel 4 menunjukkan bahwa tingkat persentase 57,69 dengan nilai frekuensi 15 pada kategori tidak tuntas, tingkat persentase 42,31 dengan nilai frekuensi 11 pada kategori tuntas. Ketuntasan secara klasikal belum mencapai $80 \%$.

B. Hasil Data Siklus II

Tabel 5. Data Frekuensi dan Persentase Hasil Belajar Matematika

\begin{tabular}{|l|l|c|c|}
\hline \multicolumn{1}{|c|}{ Nilai } & \multicolumn{1}{|c|}{ Kategori } & Frekuensi & Persentase \% \\
\hline $94 \% \leq \mathrm{TP} \leq 100 \%$ & sangat baik & 9 & 31,62 \\
\hline $87 \% \leq \mathrm{TP}<93 \%$ & baik & 8 & 30,77 \\
\hline $80 \% \leq \mathrm{TP}<86 \%$ & cukup & 6 & 23,08 \\
\hline $\mathrm{TP}<80 \%$ & kurang & 26 & 11,53 \\
\hline \multicolumn{2}{|c|}{ Jumlah } & 100 \\
\hline
\end{tabular}

(Sumber: Hasil Analisis Data, 2021)

Tabel 5 menunjukkan bahwa tingkat persentase 31,62 dengan nilai frekuensi 9 (sangat baik), tingkat persentase 30,77 dengan nilai frekuensi 8 (baik), tingkat persentase 23,08 dengan nilai frekuensi 6 (kurang), tingkat persentase 11,53 dengan nilai frekuensi 3 (kurang). Hal ini proses pembelajaran dengan tingkat penguasaan materi telah mencapai standar KKM 80.

Tabel 6. Ketuntasan Belajar Siswa

\begin{tabular}{|c|c|c|c|}
\hline Skor & Kategori & Frekuensi & Persentase \% \\
\hline $0-79$ & Tidak tuntas & 3 & 11,53 \\
$80-100$ & Tuntas & 23 & 88,47 \\
\hline \multicolumn{2}{|c|}{ Jumlah } & 26 & 100 \\
\hline
\end{tabular}

(Sumber: Hasil Analisis Data, 2021)

Tabel 6 menunjukkan bahwa tingkat persentase 11,53 dengan nilai frekuensi 3 pada kategori tidak tuntas, tingkat persentase 88,47 dengan nilai frekuensi 23 pada kategori tuntas. Ketuntasan secara klasikal telah mencapai $80 \%$.

Tabel 7. Hasil pengamatan proses pembelajaran

\begin{tabular}{|c|l|c|c|c|c|c|c|c|c|}
\hline \multirow{2}{*}{ No. } & \multicolumn{1}{|c|}{ Aspek yang dinilai } & \multicolumn{3}{|c|}{ Nilai } & \multicolumn{3}{c|}{ Nilai } \\
\cline { 3 - 9 } 1 & & 1 & 2 & 3 & 4 & 1 & 2 & 3 & 4 \\
\hline & $\begin{array}{l}\text { Keaktifan siswa dalam menjawab } \\
\text { soal-soal yang diberikan guru baik } \\
\text { secara kelompok maupun individu. }\end{array}$ & & $\sqrt{ }$ & & & & & $\sqrt{ }$ & \\
\hline 2 & $\begin{array}{l}\text { Guru memberikan kesempatan } \\
\text { kepada siswa untuk mengembangkan } \\
\text { keterampilan. }\end{array}$ & & & $\sqrt{ }$ & & & & & $\sqrt{ }$ \\
\hline 3 & $\begin{array}{l}\text { Guru menggunakan alat bantu dan } \\
\text { sumber belajar yang beragam. }\end{array}$ & & $\sqrt{ }$ & & & & $\sqrt{ }$ & \\
\hline
\end{tabular}




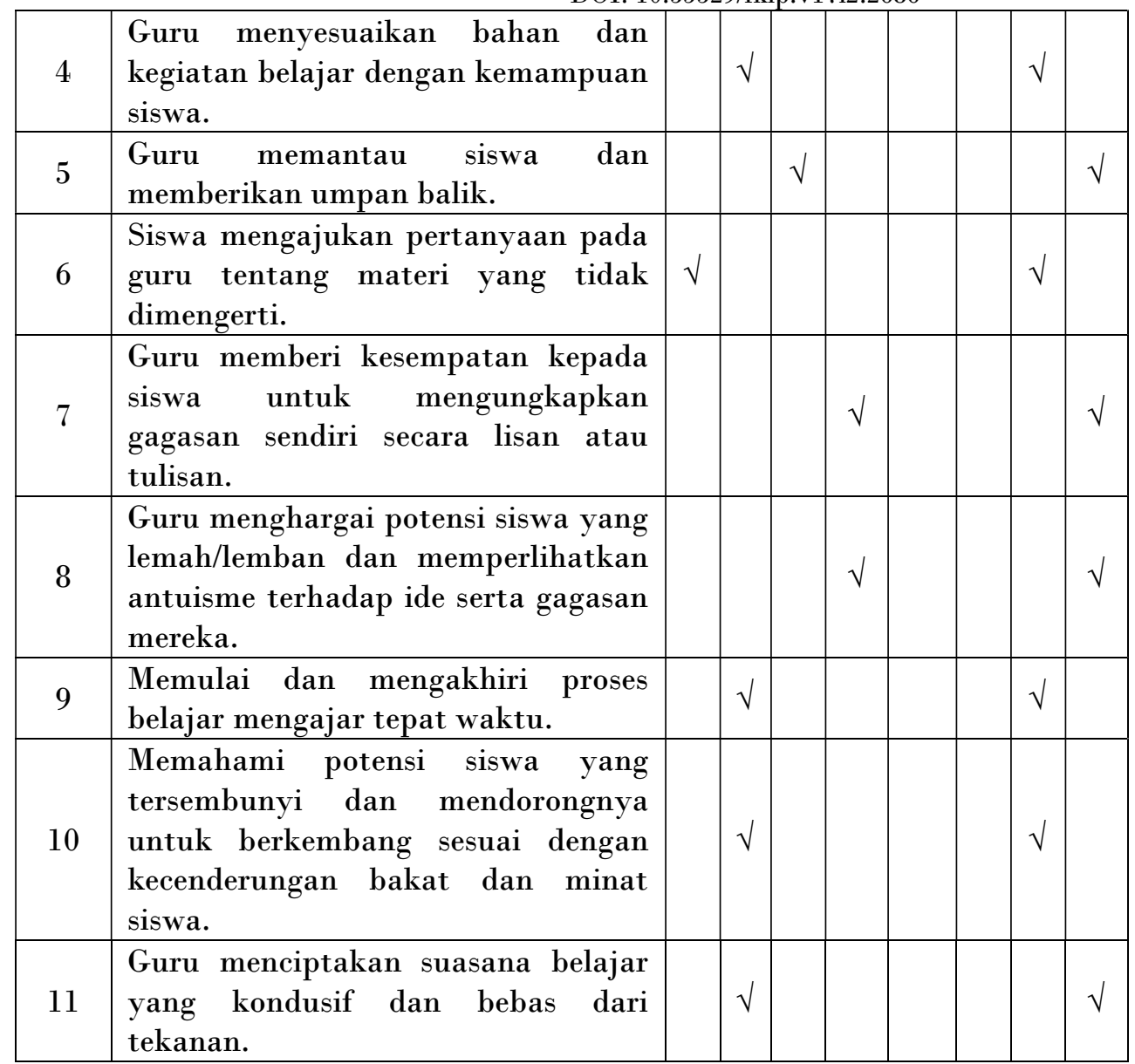

(Sumber: Hasil Analisis Data, 2021)

C. Refleksi

Sebelum melakukan penelitian di sekolah khususnya dikelas maka peneliti memberikan soal kepada siswa untuk diselesaikan sebelum penerapan model pembelajaran Problem Based Learning melalui pendekatan saintifik bertujuan untuk mengetahui permasalahan menyelesaikan soal dan bekerja secara beekelompok.

Pada siklus 1 kecendrugan siswa dalam proses pembelajaran model Problem Based Learning melalui pendekatan saintifik hal baru bagi mereka. Sehingga siswa bingung dalam menyelesaikan permasalahan dalam dunia nyata sendiri. Adapun siswa yang kurang memperhatikan penjelasan guru dan malu bertanya kepada guru pada proses pembelajaran berlangsung. Banyak hal yang terjadi dilapangan pada saat penelitian. Sehingga mengakibatkan tes hasil belajar matematika sangat kurang dan tidak mencapai standar KKM.

Pada siklus II siswa telah terbiasa dalam proses pembelajaran model 
Problem Based Learning melalui pendekatan saintifik. Sehingga siswa bersemangat dan termotivasi mengikuti proses pembelajaran berlangsung. Pada kemampuan siswa dalam menyelesaikan masalah lebih aktif baik itu secara berkelompok maupun dalam individu. Hal ini mengakibatkan pada tes akhir pembelajaran siswa meningkat dan telah mencapai standar KKM

PBL adalah sebuah model pembelajaran yang menjelaskan tentang masalah kontekstual sehingga peserta didik untuk belajar". Dalam ruangan kelas yang menerapkan pembelajaran berbasis masalah, peserta didik bekerja dalam tim untuk memecahkan masalah yang berkaitan dengan materi pembelajarannya (Sani 2014).

Pembelajaran berbasis masalah adalah model pembelajaran yang sulit siswa untuk belajar bagaimana bekerja dalam kelompok untuk melacak pengaturan dari masalah yang dia selesaikan. Seperti soal-soal yang diberikan digunakan untuk mengikat siswa ada minat belajar. Masalah diberikan kepada siswa, sebelum siswa memperoleh pengetahuan konsep atau masalah maka diberikan kesempatan untuk cari tahu masalah tersebut sebelum dipecahkan (Daryanto 2014).

Pada penerapan Problem Based Learning melalui pendekatan saintifik yaitu 1) menyajikan permasalahan dan tujuan pembelajaran 2) membantu siswa dalama mendefinisikan untuk menyelesaikan permasalahan 3) mendorong siswa untuk memperoleh informasi dan mencari solusinya 4) membantu siswa menrencanakan dan menyajikan hasil dari permasalahan 5) membantu siswa mengevaluasi penyelidikan yang mereka lakukan (Hartati and Sholihin 2015)

Dengan adanya Problem Based Learning melalui pendekatan saintifik siswa terlibat dalam kegiatan penyelesaian masalah sehingga akan bertindak aktif untuk membangun pengetahuannya dengan cara mendefinisikan permasalahan dan menganalisis. Pemilihan yang tepat dalam permasalahan akan meningkatkan keinginantahuan siswa dalam proses belajar. Maka dari itu Problem Based Learning melalui pendekatan saintifik bisa diterapkan disekolah khususnya di Sekolah Dasar.

\section{SIMPULAN}

Jenis penelitian ini menggunakan Penelitian Tindakan Kelas (PTK). Penelitian tindakan kelas ini mempunyai karekteristik di kelas dengan adanya tindakan dari tiap siklus. Tiap siklus terdiri dari 4 tahapan yaitu 1) perancanaan tindakan, 2) pelaksanaan tindakan, 3) obsevasi, 4) refleksi. Dalam tiap siklus digunakan dalam proses pembelajaran secara bersama-sama. Lokasi penelitian dilaksanakan di sekolah SD Islam 34 Al Azhar Makassar Provesnsi Sulawesi Selatan. Pelaksanaan penelitian dilaksanakan pada semester ganjil tahun ajaran 2019/2021 kelas VI dengan jumlah siswa 26 dengan jumlah siswa laki-laki 16 orang dan perempuan 11 orang. Pada siklus I ketuntasan belajar siswa pada tingkat 
persentase 57,69 dengan nilai frekuensi 15 pada kategori tidak tuntas, tingkat persentase 42,31 dengan nilai frekuensi 11 pada kategori tuntas. Ketuntasan secara klasikal belum mencapai $80 \%$. Pada siklus II ketuntasan belajar tingkat persentase 11,53 dengan nilai frekuensi 3 pada kategori tidak tuntas, tingkat persentase 88,47 dengan nilai frekuensi 23 pada kategori tuntas. Ketuntasan secara klasikal telah mencapai $80 \%$.

\section{SARAN DAN REKOMENDASI}

Untuk guru khususnya guru matematika disarankan agar di dalam proses belajar mengajar hendaknya memberikan perhatian khusus kepada siswa yang selalu melakukan aktifitas lain pada saat pelajaran berlangsung dengan cara memberikan teguran langsung yang membuat mereka termotivasi untuk belajar.

Untuk siswa diharapakan dalam penyelesaian soal tidak boleh tergesa-gesa agar nilai maksimal dan focus dalam proses pembelajaran berlangsung.

\section{DAFTAR PUSTAKA}

Anwar, Muhammad. 2015. Filsafat Pendidikan. Kencana.

Darmadi, Hamid. 2015. Desain Dan Implementasi Penelitian Tindakan Kelas (PTK). Bandung: Alfabeta.

Daryanto. 2014. Pendekatan Pembelajaran Saintifik Kurikulum 2013. Yogyakarta: Gava Media.

Hartati, Risa, and Hayat Sholihin. 2015. "Meningkatkan Kemampuan Berpikir Kritis Siswa Melalui Implementasi Model Problem Based Learning (PBL) Pada Pembelajaran IPA Terpadu Siswa SMP." Prosiding Simposium Nasional Inovasi dan Pembelajaran Sains: 1-5.

Karo-Karo, Demmu. 2016. "Meningkatkan Hasil Belajar Dengan Menggunakan Pendekatan Saintifik Pada Mata Pelajaran Matematika Di Kelas V Sd Negeri No. 107402 Saentis." Elementary School Journal PGSD FIP UNIMED $5(1)$.

Nuraini, Fivi. 2017. "Penggunaan Model Problem Based Learning (PBL) Untuk Meningkatkan Hasil Belajar IPA Siswa Kelas 5 SD." E-Jurnal mitra pendidikan 1(4): 369-79.

Paloloang, Muhammad Fachri Baharuddin. 2014. "Penerapan Model Problem Based Learning (PBL) Untuk Meningkatkan Hasil Belajar Siswa Pada Materi Panjang Garis Singgung Persekutuan Dua Lingkaran Di Kelas VIII SMP Negeri 19 Palu." Jurnal Elektronik Pendidikan Matematika Tadulako 2(1): $67-77$.

Pratama, Loviga Denny, Wahyu Lestari, and Jailani Jailani. 2018. "Implementasi Pendekatan Saintifik Melalui Problem Based Learning Terhadap Minat Dan Prestasi Belajar Matematika." JMPM: Jurnal Matematika dan Pendidikan Matematika 3(1): 11-21. 
Prayogi, Saiful, and Muhammad Asy'ari. 2013. "Implementasi Model PBL (Problem Based Learning) Untuk Meningkatkan Hasil Belajar Dan Kemampuan Berpikir Kritis Siswa." Prisma Sains: Jurnal Pengkajian Ilmu dan Pembelajaran Matematika dan IPA IKIP Mataram 1(1): 80-88.

Rusman. 2012. Model-Model Pembelajaran. Bandung: PT Rajagrafindo Perssada.

Sani, Ridwan Abdullah. 2014. Pembelajaran Saintifik Untuk Implementasi Kurikulum 2013. Jakarta: PT. Bumi Aksara.

Soedjadi. 2004. Belajar Dan Pembelajaran. Jakarta: Rineka Karya.

Sugiyono. 2019. Metode Penelitian Kualitatif, Kualitatif Dan R\&D. Bandung: Alfabeta.

Suhartini. 2009. Pendidikan Bagi Anak Kesulitan Belajar. Jakarta: PT. Raja Grafindo Persada.

Yanti, Ratni et al. 2019. "Penerapan Pendekatan Saintifik Berbantuan Geogebra Dalam Upaya Meningkatkan Pemahaman Konsep Matematis Siswa." AKSIOMA: Jurnal Matematika dan Pendidikan Matematika 10(2): 180-94. 